Article

\title{
Application of Artificial Intelligence Technologies for Diagnostics of Production Structures
}

\author{
Sergei Chernyi ${ }^{1,2,3} * *$ D , Vitalii Emelianov ${ }^{4}$, Elena Zinchenko ${ }^{2}$, Anton Zinchenko ${ }^{3}$, Olga Tsvetkova ${ }^{4}$ \\ and Aleksandr Mishin ${ }^{4}$
}

check for updates

Citation: Chernyi, S.; Emelianov, V.; Zinchenko, E.; Zinchenko, A.; Tsvetkova, O.; Mishin, A. Application of Artificial Intelligence Technologies for Diagnostics of Production Structures. J. Mar. Sci. Eng. 2022, 10, 259. https://doi.org/10.3390/ jmse10020259

Academic Editor: Claudio Ferrari

Received: 28 January 2022

Accepted: 12 February 2022

Published: 14 February 2022

Publisher's Note: MDPI stays neutral with regard to jurisdictional claims in published maps and institutional affiliations.

Copyright: (C) 2022 by the authors. Licensee MDPI, Basel, Switzerland. This article is an open access article distributed under the terms and conditions of the Creative Commons Attribution (CC BY) license (https:// creativecommons.org/licenses/by/ $4.0 /)$.
1 Department of Integrated Information Security, Admiral Makarov State University of Maritime and Inland Shipping, 198035 Saint-Petersburg, Russia

2 Department of Ship's Electrical Equipment and Automatization, Kerch State Maritime Technological University, 298309 Kerch, Russia; eltel85@bk.ru

3 Department of Cyber-Physical Systems, Saint Petersburg State Marine Technical University, 190121 Saint-Petersburg, Russia; antel85@bk.ru

4 Department of Business Informatics, Financial University under the Government of the Russian Federation, 125993 Moscow, Russia; v.yemelyanov@gmail.com (V.E.); rbtxo@mail.ru (O.T.); amishin@gmail.com (A.M.)

* Correspondence: chernysg@gumrf.ru

\begin{abstract}
The paper presents that during the operation of torpedo ladle cars in metallurgical production, problems periodically arise with ensuring the safety of their use. The authors have highlighted the relevance and necessity of the solution to the problem of diagnosing the lining state of ladle cars to ensure their safe functioning. To solve the problem of diagnosing the lining state of ladle cars for the maritime industry, an algorithm for detecting burnout zones of a lining based on a neural network has been developed. The authors propose and describe a distributed multi-agent information control system for the operation of torpedo ladle cars. The results for detecting burnout zones of a lining by the standard system and newly developed system are presented. To automate assessing the lining state of the ladle car and support in making decisions regarding operation mode of the ladle cars, the software has been developed.
\end{abstract}

Keywords: information system; maritime; neural network; diagnosing; lining

\section{Introduction}

Ships are exposed to intense corrosive effects of sea and freshwater, salt fog, atmospheric climatic factors, and industrial emissions. Difficult operating conditions place increased demands on the reliability of protective coatings and ship steels. To maintain the condition of the ship optimally, it is necessary to periodically repair and maintain that involving the role of the shipyard industry and metallurgical industry, which is engaged in ship repair and diagnosing ship steel conditions.

As part of solving the problem of energy saving in electric steel-making (converter) production for maritime industry, there is a tendency to replace stationary ladle cars for storing hot iron with torpedo ladle cars. The use of torpedo ladle cars [1,2] reduces the heat loss of hot metal on the way from the blast furnace shop to the converter plant and makes it possible to abandon the use of stationary ladle cars. It reduces the share of energy consumption by the converter shops.

However, during the operation of torpedo ladle cars in metallurgical production, problems periodically arise with ensuring the safety of their use. During the operation of torpedo ladle cars, due to the high temperatures of hot metals, there is a risk of destruction of the ladle cars, which can lead to accidents, due to which production suffers significant physical losses and damage, according to [3-5], and in some cases there are human casualties in production. Therefore, the solution to the problem of ensuring the safe functioning of torpedo ladle cars is relevant. To prevent accidents with torpedo ladle cars, 
a growing number of diagnostic operations and technologies to control the technical state are applied in production units [3,4]. Currently, the assessment of the technical state of ladle cars during their operation is conducted using measuring instruments (for example, pyrometers), the functioning of which, under the conditions of metallurgical production, is characterized by a significant measurement error as shown in [6-8]. In addition, when diagnosing torpedo ladle cars, the technologist determines the mode of their operation based on their personal experience, which causes problematic situations associated with a low level of objectivity in decision making. The solution to this problem is could be improving the means used to diagnose and monitor the technical state of ladle cars in general and their lining, in particular. Therefore, carrying out scientific research in the field of automating the assessment of the technical condition of the lining and supporting decision making during the operation of torpedo ladle cars is relevant.

\section{Literature Review}

There are some papers [9-13] in the field of automation of monitoring the ladle cars state. In paper [14], an infrared system is proposed for diagnosing the lining of a ladle. There is a LadleCheck Refractory Monitoring System [15] that allows an assessment of the remaining lifetime of the refractory lining. Scientists in the papers [16] have proposed a guide for the diagnosis of the steel ladle state. Scientists have highlighted the low level of automation to diagnose and monitor the steel ladle state.

There are different approaches $[17,18]$ to realize the maintenance procedures based on the actual state of the ladle cars. For instance, in paper [19], the applicability of 1D-CNN models in performing condition monitoring in ships was noted. In paper [20], a system with infrared control for diagnosing the state of ladle bricks is proposed.

In addition, to realize the diagnostic operations for individual facilities, a special method was created in the study [21] based on the use of thermographic results in combination with mathematical models. Authors in the study [22] present a laser meter and thermography at the steel ladle as assession methods implemented at the Nippon Steel Corporation. In paper [23], the model of steel ladles based on the thermal expansion coefficient and lining thickness was proposed and studied.

As it was analyzed previously, there are many models, methods, and ladle monitoring systems $[12,14,15,20-24]$ that automatically diagnose the technical state of critical production facilities, such as torpedo ladle cars. However, the existing models, methods, and systems do not allow the monitoring of the torpedo ladle cars without taking them out of service and do not have the possibility for preventive diagnostics. Thus, there is a necessity to improve existing models and systems for diagnosing the technical state of the torpedo ladle cars with the aim of diagnosing without taking them out of service.

\section{Algorithm for Detecting Burnout Zones of a Torpedo Ladle Car's Lining Based on a Neural Network}

To improve the diagnostic tools and monitoring the technical state of ladle cars, the authors propose an algorithm for detecting burnout zones of the lining based on the recognition of thermogram images in this paper. The novelty of this approach is that realizing the proposing algorithm diagnoses the technical state of the torpedo ladle cars without taking them out of service. This result is achieved through the use of an infrared approach and neural networks.

The algorithm includes six main stages:

Stage 1. At the first step, images of thermograms of torpedo ladle cars are formed by thermal imagers.

Stage 2. Improving the quality of the image. The implementation of the second stage of the method is due to the fact that often in the image of thermograms, there are distortions in certain local neighborhoods, which are caused by diffraction of light, defocusing, and dustiness around the thermal imager. This requires performing local transformations to highlight informative areas on the thermogram of a torpedo ladle car. 
Stage 3. After improving the image quality, the informative segments of the thermogram are separated from the background to identify areas of burnout of the torpedo ladle car.

Stage 4. At this stage, the vectorization of the selected segments characterizing the potential burnout zones of the lining and hull is carried out for their further recognition.

Stage 5 and Stage 6 . At this stage, the vectorization of the selected segments marking the potential burnout zones of the lining and casing is carried out for further recognition.

After the formation of the thermogram, to solve the problem of its contrasting, it is proposed to use the method of adaptive transformation of local contrast [25]. The main goal is to convert images to a more contrasty form. According to this method, the main features of the local neighborhood of a pixel are the length of the histogram, the entropy, or the standard deviation of brightness. In this paper, to contrast the thermogram as a specific feature of the local neighborhood of the pixel, it is proposed to use the length of the histogram [26].

The next step is to separate the background from the informative segments of the thermogram of the torpedo ladle car, which indicate a possible burnout of the lining and casing of the object. This operation is proposed to be carried out not by changing the contrast, but by using filtration methods. The authors used the following filtering methods in their paper, namely: Prewitt, Sobel, Roberts, Laplacian-Gaussian filters, and the Canny method. The filters under consideration were chosen to solve this problem due to their high efficiency in dealing with the tasks of identifying the boundaries and outlines of objects in the image $[9,10]$. In the course of the study, the analysis of the filtration results obtained showed that it is expedient to use the Sobel and Prewitt filters to separate the informative segments of the thermogram of the torpedo ladle car from the background.

After filtering, a set of informative features is formed. It characterizes the image segments of the ladle car thermogram. The elements of the segment are formed according to the technique developed by the authors in [27] using the hypotenuses of triangles, which are formed by means of perpendiculars omitted from two adjacent base points. The values of the sine and cosine of the segment elements are the input of the neural network for training. Also, the Prewitt gradient is the input parameter.

To solve the problems of classification of the ladle car thermograms, the following types of neural networks were investigated: multilayer perceptron and radial basis function network. In the study, a classical NN-based approach was chosen because deep learning is a resource-intensive technology that requires powerful GPUs, large memory, and takes more time to train.

The choice of such neural network architectures is due to the wide applicability of these networks and their high efficiency for solving problems of classification and image recognition, which follows from the analysis of sources [28,29]. In cases that do not necessarily need to have multiple neuron-hidden layers to be robust to noise, it is possible to use RBF networks. Commonly-used types of neural networks, such as multilayer perceptron, are highly vulnerable to noise and can make wrong classifications when fed with noising inputs. This fact is not the case in RBF networks. The multilayer perceptron is used to solve problems that require supervised learning and parallel processing.

It is proposed to use a multilayer neural network, which has an input layer, a hidden layer, and an output layer of neurons. The size of the hidden layer depends on the number of processing segments that label burnout zones. The size of the output layer is determined by the number of lining sections examined for burnouts.

The structure of a neural network for recognizing burnout zones on the thermogram of a torpedo ladle car is shown in Figure 1.

To train the neural network, an error backpropagation algorithm with a sigmoidal activation function was chosen [29]. To simulate the neural network shown in Figure 1, the following varieties of this learning algorithm, implemented in the MATLAB environment, were used:

- "traincgb"-Powell-Beale conjugate gradient method;

- "traincgp"-Polak-Ribiere conjugate gradient method; 
- "traingd"-gradient descent method;

- "traingda"-gradient descent method with adaptive training (with the learning rate correction).

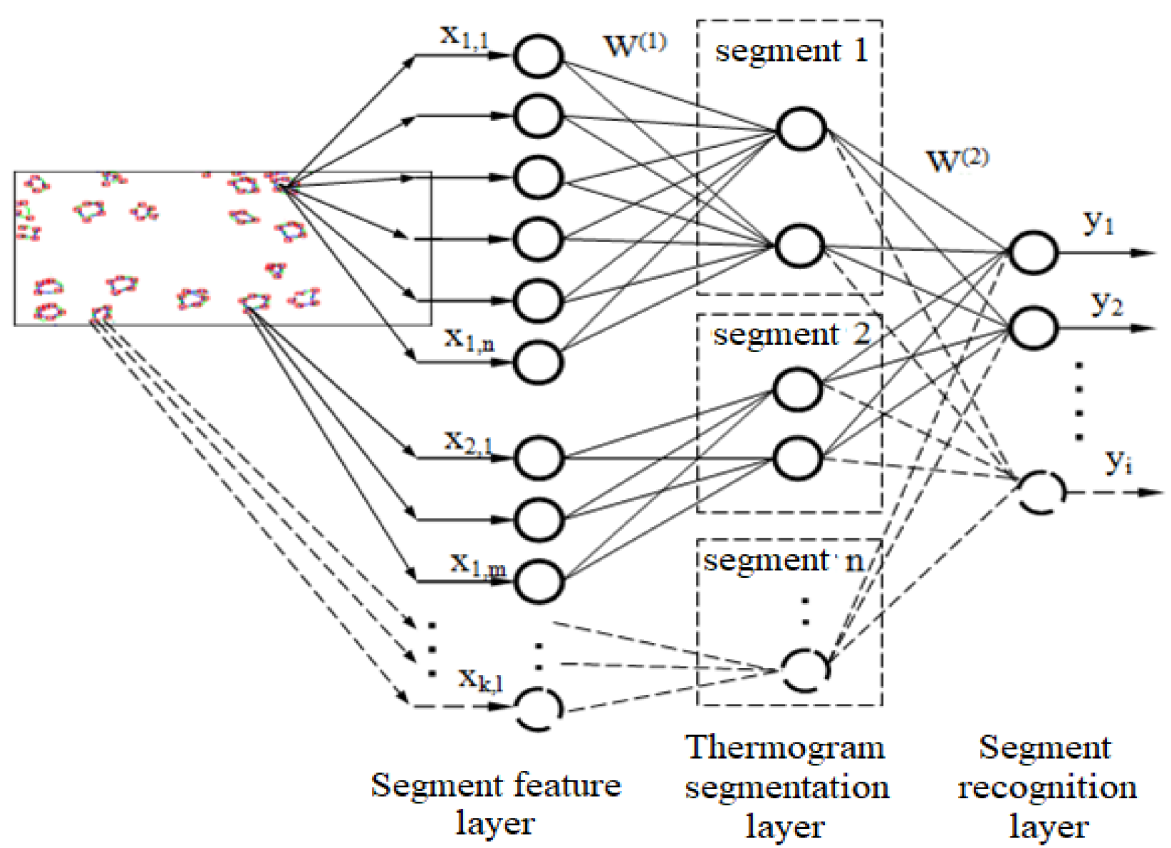

Figure 1. The structure of a multi-segment neural network for segmentation and recognition of the torpedo ladle car thermogram.

Since it is necessary for the neural network to learn to generalize rather than to memorize one separate image of the ladle car, experiments with different numbers of input and, accordingly, hidden neurons, are performed in this study. The results of experiments in the MATLAB environment are summarized in Table 1.

Table 1. Comparative results of the functioning of the developed neural networks.

\begin{tabular}{cccc}
\hline \multicolumn{2}{c}{ NN Type and Its Structure } & $\begin{array}{c}\text { An Evaluated } \\
\text { Optimal Number of } \\
\text { Learning Epochs }\end{array}$ & $\begin{array}{c}\text { Total Number of Recognizable } \\
\text { Images of Thermograms for } \\
\text { Torpedo Ladle Car }\end{array}$ \\
\hline & $510-170-40$ & 480 & $\begin{array}{c}\text { Percentage of Correctly Recognized } \\
\text { Images of Thermograms among the } \\
\text { Total Number of Thermograms }\end{array}$ \\
\cline { 2 - 4 } & $800-300-30$ & 820 & 1200 \\
\hline $\begin{array}{c}\text { Multi-segment } \\
\text { MLP-network }\end{array}$ & $900-300-20$ & 900 & 1200 \\
\cline { 2 - 4 } & $660-220-20$ & 1000 & 1200 \\
\hline & $510-170-40$ & 650 & 1200 \\
\hline $\begin{array}{c}\text { Multi-segment } \\
\text { RBF-network }\end{array}$ & $800-300-30$ & 700 & 1200 \\
\hline & $900-300-20$ & 1000 & 1200 \\
\hline
\end{tabular}

The neural network was trained on the basis of reference images of thermograms obtained experimentally at Public Joint Stock Company "Alchevsk Iron and Steel works". The training sample consisted of 1200 images of thermograms, with 600 "correct" and 600 "incorrect" ones. The "correct" one refers to images of reference thermograms of torpedo ladle cars, and "incorrect" refers to examples of noise-distorted images of standards, which, as a result, leads to incorrect recognition (classification) of the image by the neural network. Thus, the neural network was trained to misrecognize, i.e., respond to incorrect images. As a control and test sample, 640 images of torpedo ladle cars PM 350t thermograms used at the Public Joint Stock Company "Alchevsk Iron and Steel Works" were used for 
each sample. Graphs of changes in the value of training and recognition errors for the neural network above are shown in Figure 2.
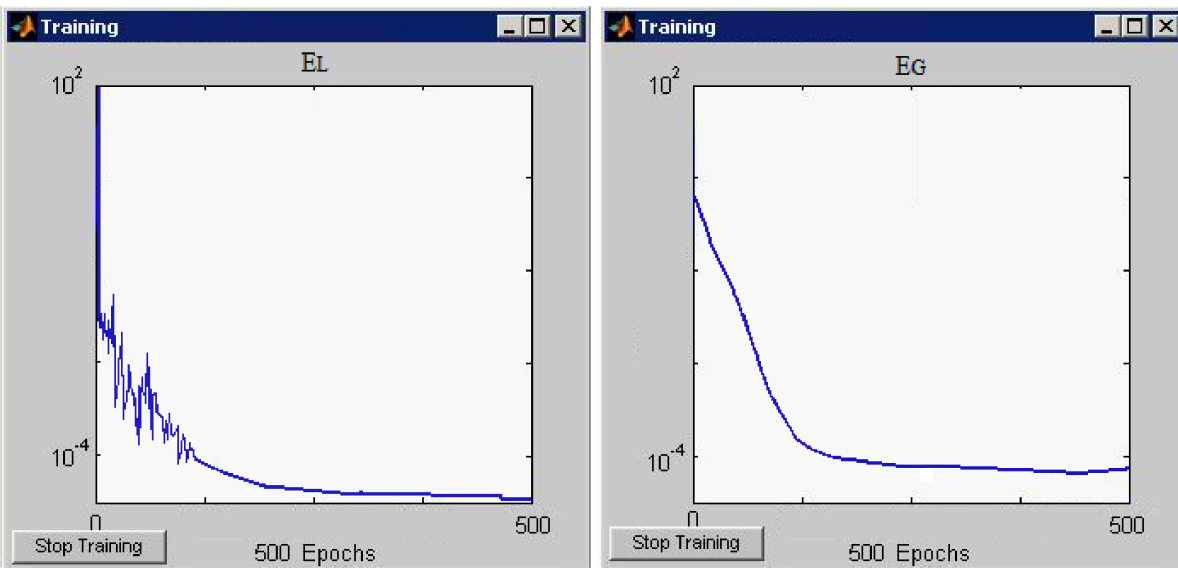

Figure 2. Graphs of changes in the dependence of the learning error (el) and recognition error (eg) on the number of learning epochs.

As a result, the optimal number of learning epochs was determined, based on the graphs of error changes. As can be seen from Figure 2, the number was equal to 480 epochs for a mentioned neural network structure since, for 480 epochs, the recognition error increases. In this case, the standard deviation was 0.011 .

As a result, the optimal number of training epochs was determined, which amounted to: "gd" - 480 epochs; "gda"—450 epochs; "cgp"—400 epochs; "cgb"—550 epochs.

The results of the functioning of the developed neural networks are summarized in Table 1.

Based on the analysis of the results of the functioning of the developed neural networks, it can be concluded that, for the stage of recognizing images of thermograms of torpedo ladle cars, it is most rational to use RBF networks.

Since the input parameters for the proposed multi-segment architecture of the neural network characterize the image of the thermogram of a torpedo ladle car and describe it quantitatively, based on the experiments with the images of thermograms, the numerical membership of the ladle car section to a certain temperature range was evaluated, depending on its input characteristics (color), by calculating the values of the output neurons during training, which are responsible for identifying burnout zones. The results are summarized in Table 2.

According to the normative data for the operation of torpedo ladle cars, values that exceed the temperature ranges T7-T10 are unacceptable. After these temperatures, metal tempering can take place, which can lead to the destruction of the torpedo ladle car. Thus, the neural network determines not only the section of the torpedo ladle car for replacement, but also the current state of a particular section.

Based on the table and the results of processing the thermogram image by the neural network, it seems possible to construct a matrix of states of the lining sections of a torpedo ladle car:

$$
\text { Places }=\left(\begin{array}{llllllll}
4 & 0 & 0 & 5 & 5 & 5 & 0 & 0 \\
0 & 0 & 0 & 0 & 4 & 5 & 0 & 0 \\
0 & 0 & 0 & 0 & 0 & 0 & 0 & 0 \\
4 & 0 & 0 & 0 & 3 & 4 & 0 & 0 \\
4 & 0 & 0 & 0 & 0 & 0 & 0 & 0 \\
4 & 0 & 0 & 0 & 3 & 0 & 0 & 3
\end{array}\right)
$$


Table 2. Compliance of the values of the output neurons with the temperature of the torpedo ladle car.

\begin{tabular}{ccc}
\hline $\begin{array}{c}\text { Output Neuron } \\
\text { Value Range }\end{array}$ & Temperature Range & $\begin{array}{c}\text { The Entered Designation of } \\
\text { the Temperature Range }\end{array}$ \\
\hline- & $0-30{ }^{\circ} \mathrm{C}$ & $\mathrm{T}_{\text {normal }}$ \\
\hline- & $30-40{ }^{\circ} \mathrm{C}$ & $\mathrm{T}_{\text {pre }}$ \\
\hline $0.0001-0.15$ & $40-50{ }^{\circ} \mathrm{C}$ & $\mathrm{T} 1$ \\
\hline $0.151-0.21$ & $50-70{ }^{\circ} \mathrm{C}$ & $\mathrm{T} 2$ \\
\hline $0.22-0.28$ & $70-90{ }^{\circ} \mathrm{C}$ & $\mathrm{T} 3$ \\
\hline $0.29-0.34$ & $90-110^{\circ} \mathrm{C}$ & $\mathrm{T} 4$ \\
\hline $0.341-0.41$ & $110-150^{\circ} \mathrm{C}$ & $\mathrm{T} 5$ \\
\hline $0.42-0.5$ & $150-200^{\circ} \mathrm{C}$ & $\mathrm{T} 6$ \\
\hline $0.51-0.6$ & $200-250^{\circ} \mathrm{C}$ & $\mathrm{T} 7$ \\
\hline $0.61-0.79$ & $250-300^{\circ} \mathrm{C}$ & $\mathrm{T} 8$ \\
\hline $0.8-0.89$ & $300-350{ }^{\circ} \mathrm{C}$ & $\mathrm{T} 9$ \\
\hline $0.9-0.99$ & $350-400^{\circ} \mathrm{C}$ & $\mathrm{T} 10$ \\
\hline
\end{tabular}

Each matrix element characterizes a specific area of the torpedo ladle car lining. Zero values indicate no damage to the sections. Based on the matrix of section conditions, it is possible to create a temperature map. For this purpose, in the software developed by the authors, the GetPixel () function is used to determine the color palette on the original image of the thermogram. Then, using standard graphical tools, a grid is generated with indications of temperatures for specific areas of lined equipment. The created map of the temperatures of the lining sections, using the example of the PM 350t torpedo ladle car, is shown in Figure 3.

\begin{tabular}{|l|l|l|l|l|l|l|l|}
\hline T2 & T2 & & & T5 & T5 & & \\
\hline T2 & T5 & T4 & & T5 & T5 & & \\
\hline T2 & & & & T2 & T3 & & \\
\hline T5 & T3 & T4 & & T3 & T3 & & \\
\hline T5 & T5 & & T5 & T5 & T4 & & \\
\hline
\end{tabular}

Figure 3. Temperature map of the thermogram image characterizing the damaged sections of the torpedo ladle car.

As a criterion for assessing the adequacy of a neural network for determining burnout zones of a real object, the value of the difference between the calculated (according to the neural network model) and experimental data is used:

$$
R=\frac{1}{\mathrm{~m}} \sum_{j=1}^{m}\left|y_{j}^{\text {model }}-y_{j}^{e p}\right| \leq R_{\text {accept }}
$$

where $y_{j}^{M}, y_{j}^{e l}$ are the model and experimental values of indicators, respectively and $R_{\text {accept }}$ is the acceptable variation.

The results of checking the adequacy of the multi-segment neural network for determining the state and burnout zones of the lining are summarized in Table 3. 
Table 3. Results of checking the adequacy of the neural network model.

\begin{tabular}{ccccc}
\hline Torpedo Ladle Car & $\begin{array}{c}\text { Temperature Values of the Sections } \\
\text { of the Torpedo Ladle Car Casing, } \\
\text { Calculated by the Neural Network }\end{array}$ & $\begin{array}{c}\text { Temperature Values of the Sections } \\
\text { of the Torpedo Ladle Car Casing, } \\
\text { Confirmed Experimentally }\end{array}$ & $\boldsymbol{R}^{-}$ & $\boldsymbol{R}_{\text {accept }}$ \\
\hline $\begin{array}{c}\text { Torpedo ladle car } \\
\text { PM 350t-No.1 }\end{array}$ & 45 & 51 & $6^{0}$ & $10^{0}$ \\
\hline $\begin{array}{c}\text { Torpedo ladle car } \\
\text { PM 350t-No.2 }\end{array}$ & 48 & 50 & $2^{0}$ \\
\hline$\ldots$
\end{tabular}

Thus, the created model of a multi-segment neural network for determining the state and burnout zones of the lining is adequate for real objects. In addition, the neural network determines not only the section of the ladle car for replacement, but also the current state of a particular section.

\section{Distributed Multi-Agent Information Control System for the Operation of Torpedo Ladle Cars}

The previously proposed neural network approach to the recognition of thermograms of torpedo ladle cars was used as the basis for the functioning of the information system developed by the authors.

The proposed system is a set of interconnected software components that implement the functions of different types of agents, reflecting the interests of diagnostic and monitoring points for lined equipment. Each subject of diagnostic activity is represented in the system by one or more software agents. Each software agent represents, in a virtual environment, some application registered on one of the portals. During the operation of the system, the agent interacts with the end user through the portal, submitting the results of its activities for consideration or requesting clarifying information about the operations of technical diagnostics of torpedo ladle cars declared by the user. The layout of the components of the multi-agent diagnostic system being developed is shown in Figure 4.

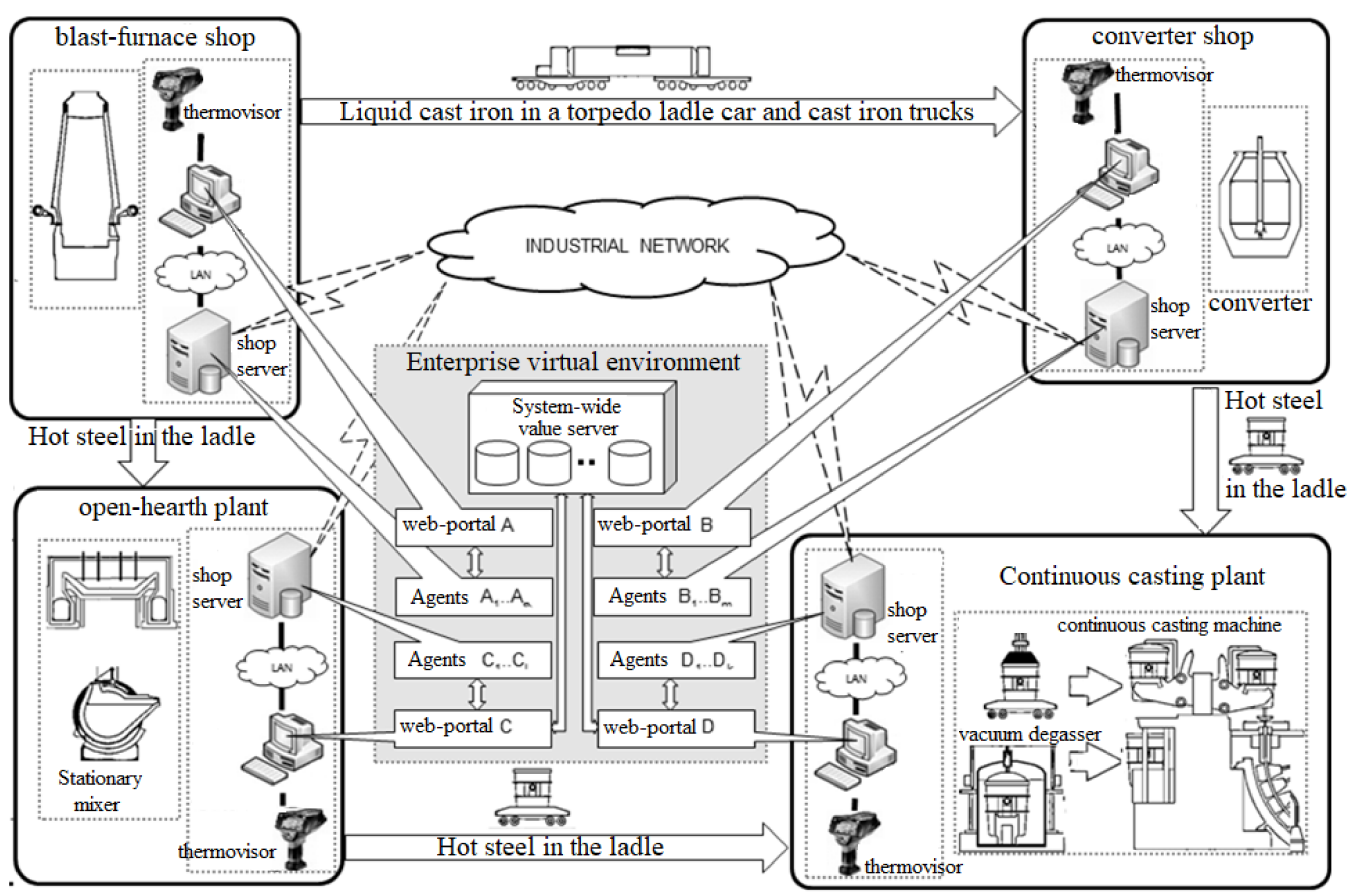

Figure 4. Layout of components of a distributed multi-agent diagnostic system for lined equipment. 
To organize the communications between network nodes of metallurgical enterprise industrial Ethernet was used. PROFINET was used as a protocol. A total of $100 \mathrm{Mbps}$ are used in industrial Ethernet for the proposed distributed multi-agent diagnostic system.

The agents of the system have a hybrid architecture with an internal modelling subsystem, which is a means of implementing the model, which helps the agent become able to search for defects in torpedo ladle cars.

As can be seen from Figure 4, agents designed to detect defects during diagnostics of torpedo ladle cars play a key role in the proposed model. In this paper, it is proposed to supplement this diagnostic system with a multitude of agents responsible for the symptoms of each type separately. The agent-based representation allows one to put forward hypotheses about possible defects (burnouts of the lining, etc.) not only after receiving information about the symptoms (casing temperature, etc.), but also at the initial stage of changes, when there is no complete confidence in the development or appearance of a symptom. In this case, each software agent becomes responsible for defects of one type, and one defect of a particular type of torpedo ladle car is recognized by only one agent. The main advantage of the proposed system based on the multi-agent approach is the possibility of parallel detection of many defects in torpedo ladle cars, which significantly increases the efficiency of the process of their diagnostics.

The multi-agent information system for monitoring and diagnostics of PM 350t torpedo ladle cars includes a technologist's computer with a client software part and a workshop server for processing information regarding the technical condition of all types of lined equipment. The server part of the specialized software includes a software analyzer of thermogram images [30] and an expert system for assessing the state of torpedo ladle cars for generating control recommendations regarding their operating mode. The expert system determines the operating mode based on the neural network approach proposed and described by the authors in [31]. The software expert system for assessing the condition of torpedo ladle cars is shown in Figure 5.

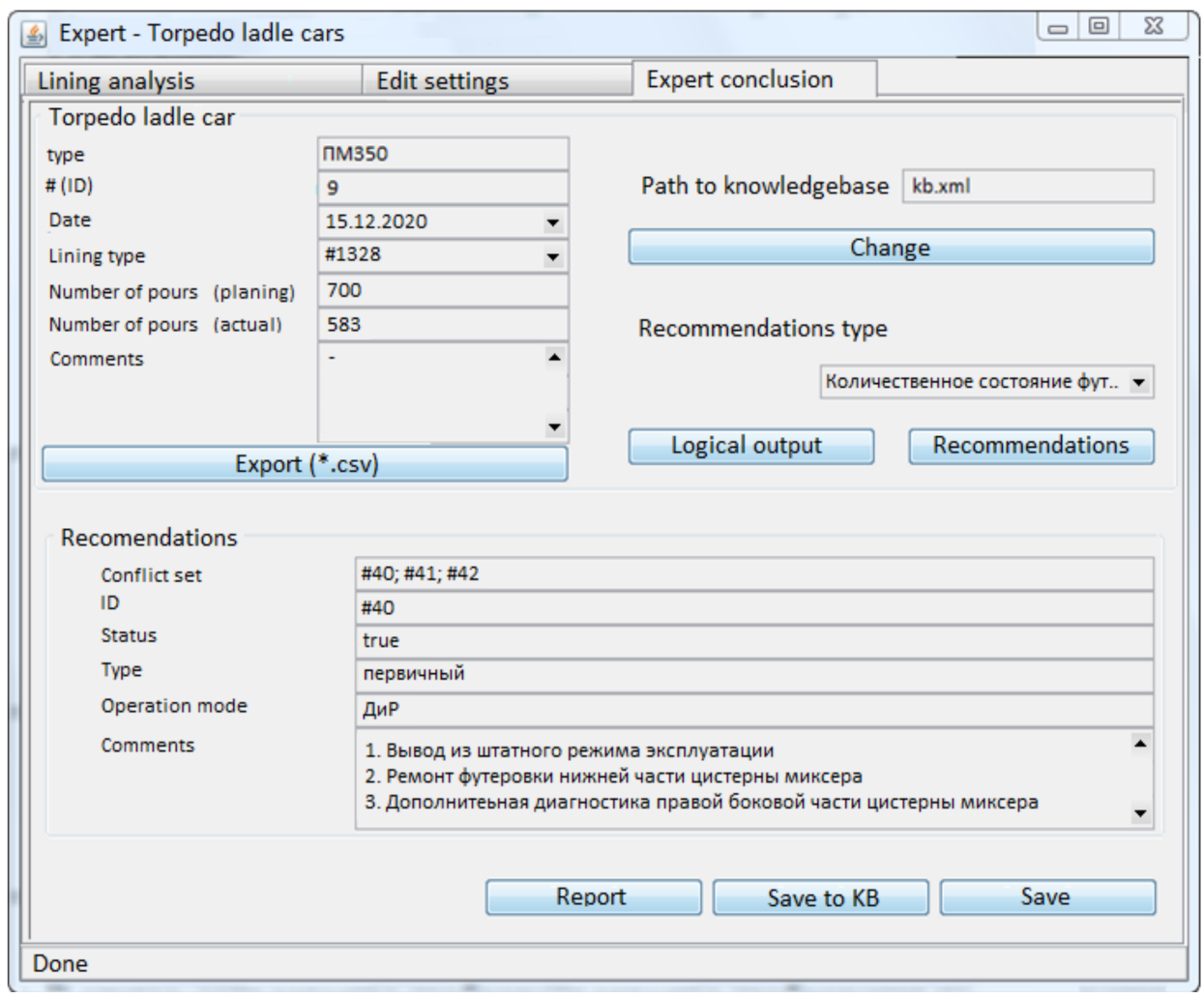

Figure 5. Software of the expert system for diagnosing the ladle car's condition. 
The functions of the software for diagnosing the ladle car's condition are as follows:

(1) receiving and input of the data on ladle cars, required in order to determine the state of the ladle car;

(2) analysis and quantitative assessment of the state of the ladle car lining based on the method proposed by the authors in the paper [31];

(3) generation of control recommendations regarding the technical condition of the lining of a torpedo ladle car and the rationality of its use using calculated data and data from regulatory documents;

(4) generation of recommendations on the type of repair and operating modes of torpedo ladle cars;

(5) creation of current and reporting documentation on the process of diagnosing the ladle cars condition;

(6) editing the knowledge base and accumulating the experience gained regarding the fleet of torpedo ladle cars in operation.

The developed software has been tested and implemented in the monitoring and diagnostics process at the metallurgical enterprise Public Joint Stock Company "Alchevsk iron and Steel Works", where torpedo ladle cars of the PM350 type are operated for transporting liquid pig iron from the blast-furnace shop to the converter shop.

\section{Result and Discussion}

To assess the effectiveness of the developed algorithm, a computer system for diagnosing the ladle cars was created. Experimental research of the developed system was carried out in the shop of "Alchevsk Iron and Steel Works".

The developed means were used to determine burnout zones of the ladle car lining. Thermal imagers were used to create thermograms' images for the torpedo ladle car PM350. To recognize the ladle car thermograms, which is demonstrated in Figure 6, the developed software was used.
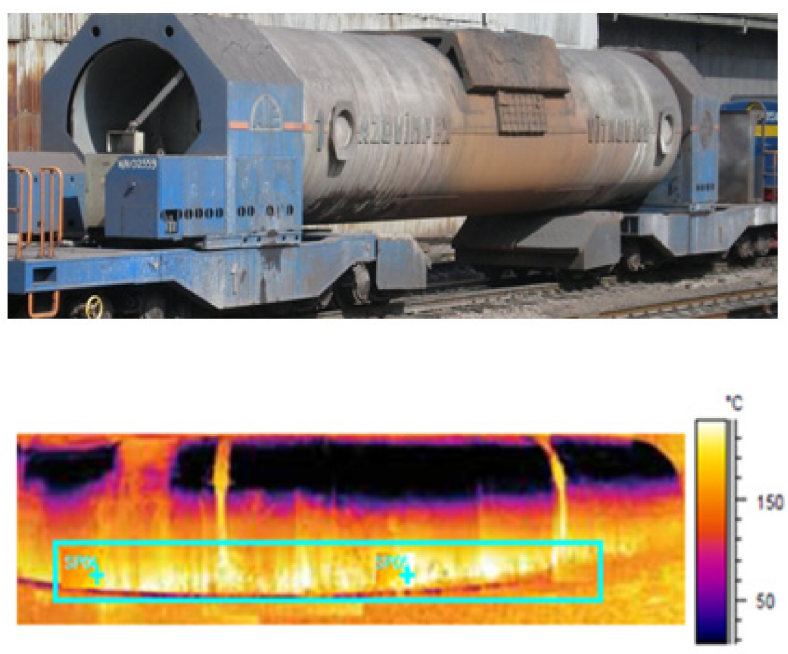

Figure 6. Thermogram of the torpedo ladle car PM350.

Let us consider the effectiveness of the developed system for diagnostics of the torpedo ladle car as compared with the standard system for technical diagnostics of ladles used at Public Joint Stock Company "Alchevsk Iron and Steel Works". To do this, we will assess the reliability of the functioning results of the created system based on calculating the error of the results using the example of determining the main operational characteristics of torpedo ladle cars, namely, the amount of permissible pouring of liquid metal into a ladle car. We will also consider the results of an experimental study of the standard system for technical diagnostics of ladle cars and the developed information system used at Public Joint Stock Company "Alchevsk Iron and Steel Works". The calculation of the error in 
determining the permissible pouring of liquid metal into the torpedo ladle car is carried out according to the Formula (3).

$$
\delta_{w}=\frac{\Delta w}{w_{\text {real }}} \cdot 100 \%
$$

where $\Delta w$ is the difference between the real value of the diagnosed parameter of the steelpouring ladle and the calculated value using the proposed information system and $w_{\text {real }}$ is the real value of the diagnosed parameter of the steel-pouring ladle.

The results of an experimental study of both systems in relation to the problem of determining the number of permissible pouring of liquid metal into a torpedo ladle car are given in Table 4.

Table 4. Experimental determination of the amount of permissible pouring of liquid metal into ladle cars using a standard system and a developed information system.

\begin{tabular}{|c|c|c|c|c|c|c|}
\hline \multirow{2}{*}{$\begin{array}{l}\text { No. of the } \\
\text { Experiment }\end{array}$} & \multicolumn{3}{|c|}{$\begin{array}{c}\text { Standard System for Diagnostics and } \\
\text { Monitoring of Ladle Cars }\end{array}$} & \multicolumn{3}{|c|}{$\begin{array}{c}\text { Information System Proposed by } \\
\text { the Authors }\end{array}$} \\
\hline & $n_{\text {count }}$ & $n_{\text {real }}$ & $\delta_{w}$ & $n_{\text {count }}$ & $n_{\text {real }}$ & $\delta_{w}$ \\
\hline$\# 1$ & 440 & 520 & 15.4 & 1100 & 1110 & 0.9 \\
\hline \#2 & 350 & 361 & 3.05 & 750 & 803 & 6.6 \\
\hline \#3 & 300 & 310 & 3.23 & 800 & 810 & 1.2 \\
\hline$\# 4$ & 290 & 310 & 6.45 & 500 & 512 & 2.3 \\
\hline \#5 & 710 & 800 & 11.3 & 50 & 53 & 5.7 \\
\hline$\ldots$ & $\ldots$ & $\ldots$ & $\ldots$ & $\ldots$ & $\ldots$ & $\ldots$ \\
\hline \#55 & 50 & 80 & 37.5 & 250 & 277 & 9.8 \\
\hline \#56 & 90 & 115 & 21.7 & 250 & 255 & 2 \\
\hline \#57 & 100 & 190 & 47.4 & 150 & 155 & 3.2 \\
\hline \#58 & 90 & 121 & 25.6 & 650 & 705 & 7.8 \\
\hline \#59 & 310 & 364 & 14.8 & 600 & 605 & 0.8 \\
\hline \#60 & 360 & 426 & 15.5 & 400 & 410 & 2.4 \\
\hline
\end{tabular}

The tables use the following designations: $n_{\text {count }}$ is the calculated number of allowable pouring operations using the system; $n_{\text {real }}$ is the experimentally confirmed number of allowable pouring operations.

Analysis of the experimental data from Table 4 suggests that in the standard system of technical diagnostics of ladle cars, the error in determining the number of permissible pouring of liquid metal into ladle cars can reach $47.4 \%$. Thus, in the information system proposed by the authors, this error does not exceed $9.8 \%$.

The experimental data in Table 4 indicate that in the proposed diagnostic information system in $96.7 \%$ of cases (58 out of 60 ), the value of the number of permissible pouring operations was correctly calculated, and in the standard technical diagnostic system, it was performed only in $89 \%$ of cases (96 out of 108).

To assess the reliability of differences between the systems, a method for assessing the reliability of the results of a statistical study, based on the Student's $t$-test, was used [32].

The following equation determines the errors of representativeness and the number of degrees of freedom:

$$
\begin{gathered}
m_{1}=\sqrt{\frac{p_{1} \cdot q_{1}}{n_{1}}}=\sqrt{\frac{96.7 \cdot(100-96.7)}{60}}=2.31 \\
m_{2}=\sqrt{\frac{p_{2} \cdot q_{2}}{n_{2}}}=\sqrt{\frac{89 \cdot(100-89)}{108}}=3.01
\end{gathered}
$$




$$
k=n_{1}+n_{2}-2=60+108-2=166
$$

where $n_{1}, n_{2}$ are volumes of compared samples.

To determine the reliability of the difference between systems $P_{1}$ and $P_{2}$ :

$$
t=\frac{P_{1}-P_{2}}{\sqrt{m_{1}^{2}+m_{2}^{2}}}=\frac{96.7-89}{\sqrt{2.31^{2}+3.01^{2}}}=2.03
$$

where $P_{1}$ and $P_{2}$ are values of the compared arithmetic means for the standard system and the developed system, and $m_{1}, m_{2}$ are the corresponding values of statistical errors of arithmetic means for the standard system and the developed system.

The value of $t$ obtained in the experiment is greater than the tabular value of $t_{0.01}$, therefore, the differences between $P_{1}$ and $P_{2}$ can be considered significant at $p<0.01$. Thus, the reliability of the differences between options $P_{1}$ and $P_{2}$ suggests that the developed information system for technical diagnostics and monitoring of ladle cars turned out to be more effective than the standard system in determining the main operational characteristic — the amount of permissible pouring of liquid metal into torpedo ladle cars.

\section{Conclusions}

In the course of the study, the following results were obtained.

1. An algorithm for detecting burnout zones in the lining of torpedo ladle cars is proposed. When developing the algorithm, a multilayer neural network model was synthesized to determine the burnout zones of the lining. The designed neural network makes it possible to determine not only a specific section of the lining of a torpedo ladle car for its replacement, but also assesses the current state of a specific section.

2. An information control system for the operation of torpedo ladle cars is proposed. It is based on the parallel detection of defects by agents, which makes it possible to increase the efficiency of diagnostics of torpedo ladle cars on the scale of the entire metallurgical enterprise. When developing the information system, the authors created an expert system software for assessing the condition of torpedo ladle cars.

As it can be seen from the analysis of the data in Table 4, after the implementation of the proposed tools, the efficiency of the functioning of the developed system for diagnostics of PM350 torpedo ladle car has been increased, and the error in determining the amount of permissible pouring of liquid metal into ladle cars does not exceed $9.8 \%$.

The novelty of this approach is that realizing the proposing algorithm allows the diagnosis of the technical state of the torpedo ladle cars without taking them out of service. This result is achieved through the use of an infrared approach and neural networks.

Author Contributions: Conceptualization, S.C. and V.E.; methodology, S.C., V.E. and E.Z.; software, A.Z.; validation, O.T., A.M. and A.Z.; formal analysis, S.C.; investigation, V.E.; resources, V.E.; data curation, S.C.; writing-original draft preparation, E.Z.; visualization, A.M.; supervision, O.T.; project administration, V.E.; funding acquisition, A.Z. All authors have read and agreed to the published version of the manuscript.

Funding: The research was partially funded by the Ministry of Science and Higher Education of the Russian Federation as part of the World-Class Research Center program: Advanced Digital Technologies (contract No. 075-15-2020-903 dated 16 November 2020).

Institutional Review Board Statement: Not applicable.

Informed Consent Statement: Not applicable.

Conflicts of Interest: The authors declare no conflict of interest. 


\section{References}

1. Bizhanov, A.; Chizhikov, V. Agglomeration in Metallurgy; Springer: Berlin/Heidelberg, Germany, 2020. [CrossRef]

2. Dutta, S.K.; Chokshi, Y.B. Basic Concepts of Iron and Steel Making; Springer: Berlin/Heidelberg, Germany, 2020. [CrossRef]

3. Hu, W.; Gu, F.; Chen, S. Large Data and AI Analysis Based Online Diagnosis System Application of Steel Ladle Slewing Bearing. In Advances in Asset Management and Condition Monitoring; COMADEM; Smart Innovation, Systems and Technologies; Springer: Berlin/Heidelberg, Germany, 2019; Volume 166, pp. 1519-1527.

4. $\quad$ Emil, M.; Venko, P.; Ivan, D.; Kosta, B. Model-Based Approach for Investigation of Ladle Lining Damages. In International Review of Mechanical Engineering; Indian Institute of Technology: Kanpur, India, 2013; Volume 7, pp. 122-130.

5. Petrova, I.; Mihailov, E.; Boshnakov, K. Decision support system for condition based maintains of steel casting ladles. J. Chem. Technol. Metall. 2019, 54, 1103-1113.

6. Chakraborty, B.; Sinha, B.K. Process-integrated steel ladle monitoring, based on infrared imaging-A robust approach to avoid ladle breakout. Quant. InfraRed Thermogr. J. 2020, 17, 169-191. [CrossRef]

7. Gordon, Y.; Kumar, S.; Freislich, M.; Yaroshenko, Y. The modern technology of iron and steel production and possible ways of their development. Steel Transl. 2015, 45, 627-634. [CrossRef]

8. Chernyi, S. Use of Information Intelligent Components for the Analysis of Complex Processes of Marine Energy Systems. Transp. Telecommun. J. 2016, 17, 202-211. [CrossRef]

9. Zhilenkov, A.; Chernyi, S.; Emelianov, V. Application of Artificial Intelligence Technologies to Assess the Quality of Structures. Energies 2021, 14, 8040. [CrossRef]

10. Yilmaz, S. Thermomechanical Modelling for Refractory Lining of a Steel Ladle Lifted by Crane. Steel Res. 2003, 74, 483-488. [CrossRef]

11. Doukovska, L.; Petkov, V.; Mihailov, E.; Vassileva, S. Image Processing for Technological Diagnostics of Metallurgical Facilities Cybern. Inf. Technol. 2012, 12, 66-76. [CrossRef]

12. Mill Ladle Refractory Monitoring. Available online: https://www.flir.com/discover/instruments/early-fire-detection/millladle-refractory-monitoring/ (accessed on 1 December 2021).

13. Metal and Steel Industry Integrated Process Route. Available online: https://cdn.sick.com/media/docs/7/47/447/industry_ guide_metal_and_steel_industry_integrated_process_route_en_im0062447.pdf (accessed on 5 December 2021).

14. Lee, S.J.; Jeon, Y.-J.; Kim, S.W. Analyzing Refractory Bricks of Ladles using Infrared Images. J. Inst. Control Robot. Syst. 2015, 21, 291-300. [CrossRef]

15. Thermal Imaging System for a Reliable Condition Monitoring of the Refractory Lining. Available online: http:/ /www.piepervideo.com/upload/pdf/downloads/LadleCheck_EN.pdf (accessed on 1 December 2021).

16. Condition Monitoring of Steel Ladles with IR Cameras. Available online: https://www.automationtechnology.de/cms/en/ condition-monitoring-of-steel-ladles / (accessed on 5 December 2021).

17. Mihailov, E.; Petkov, V.; Doichev, I.; Boshnakov, K. Model-Based Approach for Investigation of Ladle Lining Damages. Int. Rev. Mech. Eng. 2013, 7, 122-130.

18. Lamm, R.; Kirchhoff, S. Optimization of Ladle Refractory Lining, Gap and Crack Detection, Lining Surface Temperature and Sand-Filling of the Ladle-Tap Hole by Means of a 3d-Laserprofile-Measurement System That Is Immersed into a Hot Ladle to Evaluate the Entire Condition. Available online: http://www.unitecr2017.mundodecongresos.com/abstracts/Paper_ rbofbhfxcsxhpgipoispm.pdf (accessed on 1 December 2021).

19. Theodoropoulos, P.; Spandonidis, C.C.; Giannopoulos, F.; Fassois, S. A Deep Learning-Based Fault Detection Model for Optimization of Shipping Operations and Enhancement of Maritime Safety. Sensors 2021, 21, 5658. [CrossRef] [PubMed]

20. Tripathi, A.; Saha, J.K.; Singh, J.B.; Ajmani, S.K. Numerical Simulation of Heat Transfer Phenomenon in Steel Making Ladle. ISIJ Int. 2012, 52, 1591-1600. [CrossRef]

21. Petrova, I.; Mihailov, E. Determination of Defects Parameters in Infrared Diagnosis of Steel Ladle Wall. J. Chem. Technol. Metall. 2020, 55, 2158-2166.

22. Sawai, S.; Shiokawa, M.; Hashimoto, K.; Yamada, Y. Methods of Evaluating the Damage of Steelmaking Refractories; December, No. 215; Nippon Steel Technical Report; Nippon Steel: Tokyo, Japan, December 2020.

23. Li, G.F.; Xu, S.Q.; Jiang, G.Z.; Wu, Z.H.; Kong, J.Y.; Xie, L.X. Influence of Working Lining Parameters on Stress Field of Ladle Composite Construction Body. Appl. Mech. Mater. 2011, 121, 800-804. [CrossRef]

24. Zhilenkov, A.; Abramkina, K.; Epifantsev, I.; Chernyi, S. Intelligent Energy-Quality Management in Autonomous Electric-Power Systems of Transport Facilities. Russ. Electr. Eng. 2021, 92, 284-290. [CrossRef]

25. Vijayalakshmi, D.; Nath, M.K. Taxonomy of Performance Measures for Contrast Enhancement. Pattern Recognit. Image Anal. 2020, 30, 691-701. [CrossRef]

26. Dougherty, G. Pattern Recognition and Classification; Springer: Berlin/Heidelberg, Germany, 2013; p. 206.

27. Yemelyanov, V.; Yemelyanova, N.; Nedelkin, A.; Zarudnaya, M. Neural network to diagnose lining condition. IOP Conf. Ser. Mater. Sci. Eng. 2018, 327, 022107. [CrossRef]

28. Kenji, S. Artificial Neural Networks: Architectures and Applications; InTech: London, UK, 2013; p. 264.

29. Suresh Kumar, P.; Behera, H.S.; Anisha Kumari, K.; Nayak, J.; Naik, B. Advancement from neural networks to deep learning in software effort estimation. Perspect. Two Decades Comput. Sci. Rev. 2020, 38, 100288. [CrossRef] 
30. Yemelyanov, V.; Tochilkina, T.; Vasilieva, E.; Nedelkin, A.; Shved, E. Computer diagnostics of the torpedo ladle cars. AIP Conf. Proc. 2018, 2034, 020008. [CrossRef]

31. Yemelyanov, V.; Chernyi, S.; Yemelyanova, N.; Varadarajan, V. Application of neural networks to forecast changes in the technical condition of critical production facilities. Comput. Electr. Eng. 2021, 93, 107225. [CrossRef]

32. Shalabh, H.T. Statistical Analysis of Designed Experiments; Springer: Berlin/Heidelberg, Germany, 2009; p. 624. 